\title{
Annex to Quirke et al. Quality assurance in pathology in colorectal cancer screening and diagnosis: annotations of colorectal lesions
}

\author{
Michael Vieth • Phil Quirke • René Lambert • \\ Lawrence von Karsa $\cdot$ Mauro Risio
}

Received: 6 August 2010 / Accepted: 24 August 2010/Published online: 9 November 2010

(C) The Author(s) 2010. This article is published with open access at Springerlink.com

\begin{abstract}
Multidisciplinary, evidence-based European Guidelines for quality assurance in colorectal cancer screening and diagnosis have recently been developed by experts in a pan-European project coordinated by the International Agency for Research on Cancer. The full guideline document includes a chapter on pathology with pan-European recommendations which take into account the diversity and heterogeneity of health care systems across the EU. The present paper is based on the annex to the pathology chapter which attempts to describe in greater depth some of the issues raised in the chapter in greater depth, particularly details of special interest to pathologists. It is presented here to make the relevant discussion known to a wider scientific audience.
\end{abstract}

M. Vieth $(\bowtie)$

Institute of Pathology, Klinikum Bayreuth,

Preuschwitzerstr. 101,

95445 Bayreuth, Germany

e-mail: vieth.lkpathol@uni-bayreuth.de

P. Quirke

Pathology and Tumour Biology,

Leeds Institute of Molecular Medicine, Leeds University,

Leeds, UK

R. Lambert

Screening Group, Early Detection and Prevention Section, International Agency for Research on Cancer,

Lyon, France

L. von Karsa

Quality Assurance Group, Early Detection and Prevention Section, International Agency for Research on Cancer,

Lyon, France

M. Risio

Pathology Department,

Institute for Cancer Research and Treatment,

Turin, Italy
Keywords Colorectal cancer screening · Multidisciplinary evidence-based guidelines · Quality assurance . Histopathology · Classification · Precursor lesions

\section{Introduction}

In 2004 and 2006 the European Union (EU) was expanded to include 12 new Member States. This has added greater diversity and heterogeneity in health care systems, including professional and technical standards and capacities. The authors and editors of the European guidelines for quality assurance in colorectal cancer screening and diagnosis have been conscious of the importance of raising and maintaining standards across the EU. While recommending standards and procedures that are of prime importance for mortality reduction, an equitable balance of best practice and ease of service delivery that can be achieved across a wide spectrum of cultural and economic healthcare settings has been sought. Care was taken to avoid promotion of recent research findings before their putative benefit has been demonstrated in clinical practice.

In preparing the guidelines chapter with pan-European recommendations dealing with pathology [1], the authors were aware that the rapid pace of developments in the field and the diversity in the EU would not permit a discussion of some of the issues in greater depth, even though a more detailed discussion would be welcomed by a number of readers, particularly regarding items of special interest to pathologists. All of the guideline recommendations for quality assurance in pathology are therefore presented in the preceding paper and in the pathology chapter in the full guidelines document [1], on which the preceding paper is based.

The present paper is based on the annex to the chapter on pathology in the full guidelines document [2]. It attempts to address the limitations of the discussion in the 
chapter, but for the abovementioned reasons, none of the statements in the following text should be understood as guideline recommendations. The authors and editors also felt that an annex would be the appropriate place to point out new insights not yet widely adopted in Europe that may be relevant to future updates of the guidelines.

\section{Grading of neoplasia}

In the present European Guidelines [1], a classification system for colorectal neoplasia has been recommended based on a modified version of the revised Vienna classification (see Grading of Neoplasia in main publication). For readers not yet familiar with the Vienna classification, it may be helpful to note that it is the first classification to include a clinical recommendation for each neoplastic category. Furthermore, the system was developed to improve diagnostic reproducibility in the interpretation of biopsy specimens and subsequent resection specimens [3-5]. Strictly speaking, the Vienna classification is only valid for biopsy specimens, since a clinical recommendation should follow. However, to avoid diagnostic inconsistencies, the Vienna classification can be used for resection specimens as well.

In the Vienna classification and hence in the European Guidelines, the term neoplasia rather than dysplasia is used to refer to epithelial tumours associated with and without chronic inflammatory diseases. Whereas the Vienna classification differentiates between strictly intraepithelial lesions and those involving the lamina propria, the European Guidelines only refer to mucosal neoplasia that may or may not involve the lamina propria (see Grading of Neoplasia in main publication). More importantly, the EU Guidelines recommend a two-tiered grading of mucosal neoplasia. The pathologist must decide whether a neoplastic mucosal lesion can be categorised as low or as high grade; for criteria see Table 1.
As always in neoplasia, the lesion should reach the mucosal surface (no epithelial maturation). Undermining edges of an adjacent carcinoma should be excluded.

The criteria in Table 1 can be weighted. The most important criteria for the diagnosis of carcinoma are the lateral expansion and the number of nuclear rows. In carcinoma, the number of nuclear rows should change within a single gland. High-grade neoplasia is diagnosed when the nuclear rows do not exceed two to five nuclei, and the glands do not show lateral expansion. Low-grade neoplasia is diagnosed when the nuclear rows do not exceed two to three nuclei [6-8].

In histopathology, the entity of carcinoma in situ is generally defined as carcinoma confined to the epithelial layer. In squamous epithelium such an entity can be readily diagnosed. In columnar epithelium, an analogous entity should theoretically also exist. However, to date there are no exact criteria that would permit diagnosis and that would enable the histopathologist to distinguish high-grade intraepithelial neoplasia from carcinoma limited to the epithelial layer that is not invasive in the lamina propria. Therefore, throughout the gastrointestinal tract, use of the term carcinoma in situ is not recommended for respective lesions in columnar epithelium. The term intramucosal carcinoma is widely introduced in the upper GI tract but not yet in the lower GI tract (see also below: Definition of invasion). We prefer the term "mucosal neoplasia" to intraepithelial neoplasia as highgrade dysplasia can contain epithelial neoplasia and invasion into the lamina propria according to the TNM classification.

\section{Classification of serrated lesions}

\section{Terminology}

The terminology is still under discussion. Serrated lesions can be regarded as a continuous spectrum of colorectal lesions

Table 1 Grading of gastrointestinal neoplasia

\begin{tabular}{|c|c|c|c|c|}
\hline & Normal & $\begin{array}{l}\text { Low-grade mucosal/intraepithelial } \\
\text { neoplasia (LGMN) }\end{array}$ & $\begin{array}{l}\text { High-grade mucosal/intraepithelial } \\
\text { neoplasia (HGMN) }\end{array}$ & Invasive cancer \\
\hline Glands & Non-branching & Villous & Branching, cribriform, irregular, solid & $\begin{array}{l}\text { Branching, cribriform, } \\
\text { irregular, solid }\end{array}$ \\
\hline Expansion & Up/down & Till surface & Till surface & Lateral expansion \\
\hline Epithelial differentation & Up/down & Top-down and exceptional down-top & No maturation towards surface & \\
\hline Goblet cells & ++ & + & -/+ Retronuclear, atypic & \\
\hline Nuclear rows & 1 & $2-3$ & $2-5$ & Changing \\
\hline Nuclear size & Small, basal & Palisading & Enlarged & Vesicular \\
\hline Chromatin & Few & + & ++ & $++/+++$ \\
\hline Nucleoli & None & None & Few small & Several/prominent \\
\hline
\end{tabular}

Source: modified from [67-69] 
with increasingly more pronounced serrated morphology starting with a hyperplastic polyp (HP) and progressing to sessile serrated lesions (SSLs, sometimes referred to as sessile serrated adenomas or sessile serrated polyps), traditional serrated adenomas (TSA) and leading, finally, to adenocarcinoma. Not only the adenomatous component but also other alterations associated with more pronounced serrated morphology may potentially progress to cancer (see Table 2).

The situation involving sessile serrated lesions is complicated as these lesions only reveal complex structural abnormalities, not adenomatous changes. Therefore, these lesions are neither adenomatous nor are they neoplastic. This is why Kudo et al. [9] and Lambert et al. [10] recommended that these lesions no longer be called adenomas; instead they should be referred to as SSLs. Few of these lesions are reported to rapidly progress to invasive carcinoma, [11]. Those few cases that do progress rapidly, particularly in the right colon, may be expected to appear more frequently as interval cancers. TSAs, unlike SSLs, do contain adenomatous alterations, albeit sometimes quite subtle [12]; they are therefore termed correctly and treatment and surveillance should correspond to that of adenomas (see Chapters 8 and 9 in the full guideline document $[13,14])$.

Due to the continuous spectrum in the serrated pathway to colorectal cancer, lesions with combinations of serrated morphology and adenomatous cytology can be observed. If more than one histopathologic type in the serrated spectrum (HP, SSL, TSA) is discernible in a given lesion, or at least one type in combination with adenomatous tissue, such lesions are referred to as mixed polyps.

The different histopathologic types (e.g. HP and SSL, SSL and TSA, adenoma and SSL, etc.) must be stated in the diagnosis.

\section{Hyperplastic polyp}

Hyperplastic polyps (HPs) are composed of elongated crypts (no complex architecture) with serrated architecture in the upper half of the crypt. These polyps usually show some proliferation in the basal (non-serrated) part of the crypts (regular proliferation). Nuclei are small, regular, basal-orientated and lacking hyperchromasia, but with stratification of the upper (serrated) half of the crypts, and without cytological or structural signs of neoplasia.

Differences in the appearance of the cytoplasma permit recognition of three types:

- Microvesicular type

- Goblet-cell-rich type

- Mucin-poor type.

The microvesicular variant greatly predominates, but distinction between types is subject to wide interobserver variation, especially in small lesions, and is not always possible. Currently, routine subclassification is therefore neither feasible, nor has it been shown to be beneficial.

At the molecular level the microvesicular variant of HP may be the precursor lesion for sessile serrated lesion, and a goblet-cell-rich HP may be the precursor lesion for a traditional serrated adenoma [15-17]. Routine distinction of these types is not necessary.

\section{Sessile serrated lesion}

Sessile serrated lesions are described in the literature as "sessile serrated adenoma" and are often found in the right colon. This is a misnomer since sessile serrated lesions do not contain adenomatous changes $[9,10,18]$.

To date, four synonymously used terms exist for these lesions: sessile serrated adenoma [19], superficial serrated adenoma [20], type 1 serrated adenoma [21] and serrated polyp with abnormal proliferation [17].

We recommend using only the term sessile serrated lesion and avoiding use of any other terms for this entity. This recommendation is given in full awareness that sessile serrated lesions do not show histological signs of an adenoma, but, like adenomas, they should be excised if detected during an endoscopic examination. Currently, even in the hands of expert GI pathologists, the agreement on the sub-types of serrated lesions is only moderate [22].

The vast majority of SSLs will not progress to adenocarcinoma. Histological criteria of these sessile,

Table 2 Continuous spectrum of serrated lesions and possible combinations of histopathologic types

\begin{tabular}{lll}
\hline Lesion & Neoplasia & Risk of malignant transformation \\
\hline Hyperplastic polyp & No & Minimal \\
Sessile serrated lesion & No & Slightly increased but exact data are missing (rapid transformation may be possible in a short time) \\
Traditional serrated adenoma & Yes & Increased and suggested worse prognosis than carcinomas arising in sessile serrated lesions \\
Mixed polyp & Yes & Increased, but exact data are not available \\
Adenoma (tubular, villous) & Yes & Increased, 17 years on average \\
\hline
\end{tabular}

Every lesion can give rise to adenocarcinoma

Most of the adenocarcinomas are believed to derive from adenomatous components 
usually larger lesions include an abnormal proliferation zone with structural distortion, usually most pronounced in dilatation of the crypts, particularly near the base. Abundant mucus production is usually also observed as pools of mucin in the lumen of the crypts and on the surface of the mucosa. SSLs are found mainly in the right colon and may be misdiagnosed as hyperplastic polyps. Clues to the correct diagnosis include location and large size. As discussed above, cytological signs of "neoplasia" are lacking, but structural abnormalities are present, i.e. glandular branching [18].

Sessile serrated lesions have an elevated serration index and serration in the basal half of crypts with basal dilation of crypts. The epithelium/stroma-ratio is believed to be $>50 \%$ in SSL. There is crypt branching with horizontal growth (above muscularis mucosae; e.g. T- and L-shaped glands) and often pseudoinvasion into the submucosal layer, rectangular dilation of whole crypts with and without presence of mucus, increased number of goblet cells at the base of the crypts, vesicular nuclei with prominent nucleoli and proliferation zone in the middle of the crypts. Currently there is insufficient evidence available in the literature for weighting of these criteria.

A well-oriented polypectomy is mandatory for the identification of such histological features. Correct assessment of the deepest portions of the mucosa is impossible in superficial or tangentially cut lesions $[15,16]$.

Further criteria include an often asymmetrical expansion of the proliferation zone into the middle third of crypts. Often mild cytological atypia (slightly enlarged vesicular nuclei, nucleoli) is found without clear signs of neoplasia (dysplasia).

BRAF mutations depend on the type and location of lesion (see Table 3).

Other abnormalities include:

- The majority of SSL and TSA show CpG island methylator phenotype (CIMP) and promoter methylation of hMLH1

- BRAF mutations in $8-10 \%$ of all colorectal cancer (CRC; $27-76 \%$ of CIMP and sporadic MSI-H CRC)
- BRAF mutations in the majority of SSL and TSA (also microvesicular variant of HP, especially proximal), but rarely $(0-5 \%)$ in adenoma [23-34].

The frequency of sessile serrated lesions in small retrospective series is estimated at $2-11 \%$ of all mucosal lesions in the colon $[35,36]$; between $8 \%$ and $23 \%$ are misdiagnosed as hyperplastic polyps with an interobserver variation of up to $40 \%[17,37-39]$.

The histological features separating HPs from SSLs constitute a continuous spectrum, and intermingled features can often be seen. This could explain the moderate interobserver concordance $(k=0.47)$ and the overlapping proliferative activity, and may justify establishing semiquantitative criteria for diagnosis (e.g. $>30 \%$ of undifferentiated cells) [40, 41]. Only a few immunohistochemical markers (Ki67, Ki67+CK20, MUC6) have been tested for differentiating HPs and SSAs, and their usefulness in colorectal screening and diagnosis remains to be validated $[42,43]$. At present, such an additional immunohistochemical analysis cannot be recommended (see Table 4).

In all likelihood, lesions formerly interpreted as mixed hyperplastic and adenomatous polyp are, in fact, SSLs complicated by conventional neoplasia, [44]. Special care must be taken in such cases to document the respective histopathologic components in such mixed polyps. Sometimes the conventional neoplastic part shows features other than in classical adenomas. The nuclei are prominent, less palisading and smaller than in classical adenomas. It is not clear whether this type of morphology is distinct for serrated lesions and whether any clinical implications can be drawn.

Prospective studies with risk stratification are needed to develop more precise methods of diagnosis and recommendations for classification. Sessile serrated lesions appear to take a long time (average 17 years) to develop into an invasive carcinoma. In contrast, an ill-defined, small subsample of SSLs seems to rapidly progress [11, 44]. Therefore, SSLs should be completely excised, particularly if they are located on the right side of the colon $[16,45]$.

Diagnosis on a biopsy is not adequate to exclude SSL since the most severe histologic changes might only appear

Table 3 Prevalence of serrated lesions with BRAF Mutation - a prospective study of patients undergoing colonoscopy

\begin{tabular}{lccc}
\hline Lesion & Number $(n=414)(\%$ of all lesions) & Proximal location (\% of BRAF mutations) & Distal location (\% of BRAF mutations) \\
\hline Hyperplastic polyp & $120(29)$ & $35(29)$ & $85(71)$ \\
Sessile serrated lesion & $36(9)$ & $27(75)$ & $9(25)$ \\
Trad. serrated adenoma & $3(1)$ & $2(66)$ & $1(33)$ \\
Mixed polyp & $7(2)$ & $4(57)$ & $3(43)$ \\
Tubular adenoma & $237(57)$ & $176(74)$ & $61(26)$ \\
Villous adenoma & $11(3)$ & $6(55)$ & $5(45)$ \\
\hline
\end{tabular}

Source: modified from [54] 
Table 4 Comparison of proliferative activity in adenoma, hyperplastic polyps, sessile serrated lesion and traditional serrated adenoma

\begin{tabular}{lcccc}
\hline Ki-67 & Adenoma (\%) & Hyperplastic polyps (\%) & Sessile serrated lesion (\%) & Traditional serrated adenoma (\%) \\
\hline Upper $1 / 3$ & 68.8 & 0.1 & 1.6 & 27.9 \\
Middle $1 / 3$ & 48.7 & 9.1 & 20.3 & 30.6 \\
Lower $1 / 3$ & 29.6 & 60.3 & 64.9 & 38.2 \\
\hline
\end{tabular}

Source: modified from $[38,44]$

focally within a lesion that otherwise appears to be a hyperplastic polyp [46].

The German guidelines for colorectal cancer [47] recommend complete removal and follow-up of SSL similar to adenomas. An intensive surveillance protocol is recommended for sessile serrated lesions (surveillance colonoscopy after 3-5 years subsequent to complete excision of non-neoplastic SSL, after 1 year after excision of SSL HGIEN [47]).

The UK Guidelines [48-51] recommend complete excision but classify these lesions in the same risk category as hyperplastic polyps. The existing evidence base is not definitive as to the level of risk, and follow-up decisions should be made locally until more evidence is forthcoming.

\section{Traditional serrated adenoma}

Traditional serrated adenomas show neoplastic crypts with a serrated structure [52]. Compared to hyperplastic polyps, the most striking diagnostic feature of traditional serrated adenomas are the complex serrated morphology and the eosinophilic, "dysplastic" cytoplasm that still can be identified in cases with invasive adenocarcinoma. These lesions also frequently show $B R A F$ mutations and CIMP with $h M L H 1$ promoter methylation. Additionally, so-called intraepithelial microacini can be observed in the upper half of the mucosa (ectopic crypt formation). Often, these lesions are located in the distal colon and can be found more frequently in elderly female individuals [12, 18, 43].

\section{Mixed polyp}

A mixed polyp may contain partially hyperplastic, classical adenomatous or traditional serrated adenoma or sessile serrated lesion components. Rather than a continuous spectrum such lesions most probably represent several evolutionary lines, depending on the order of certain abnormalities in genes such as $A P C, B R A F$ and $K R A S[15,16]$. It has to be determined whether mixed polyps represent serrated lesions complicated by conventional neoplasia [53].

Focal, hyperplastic-like narrowing of the basal region of a few crypts in SSL and the findings of flat sectors or ectopic crypt formation in SSL/TSA [43] are examples of combinations of serrated and adenomatous components.
However, these features add no information of further diagnostic value; they probably result from the continuous developing nature of serrated lesions. We therefore recommend that the diagnosis of mixed polyp should be restricted to the definition given above under Terminology (i.e. lesions with-...more than one histopathologic type in the serrated spectrum (HP, SSL, TSA) ... or at least one type in combination with adenomatous tissue...). Mixed polyps are serrated lesions in which more than one histopathologic type in the serrated spectrum (HP, SSL, TSA) is discernible in a given lesion or at least one type in combination with classical (unserrated) adenomatous tissue. The different histopathological types must be mentioned in the diagnosis, e.g. mixed polyp (HP and SSL, adenoma and SSL).

\section{Risk of progression}

The vast majority of hyperplastic polyps and serrated lesions will not undergo malignant transformation. Only a fraction, especially in the group of sessile serrated lesions, may progress to rapidly aggressive carcinoma [35, 54].

Hyperplastic polyps rarely progress to carcinoma. A single case report can be found in the literature [55] and a second (unpublished) case has been reported in southern Germany. Interestingly, these carcinomas show features of gastric differentiation.

Little evidence is available on which the risk of colorectal cancer associated with serrated lesions other than hyperplastic polyps could be reliably judged. The risk assessment for sessile serrated lesions is not yet defined, but a subset of these lesions appears to give rise to carcinoma often less than a few millimeters in size. In a series of 110 traditional serrated adenomas, 37\% exhibited foci of significant neoplasia and $11 \%$ contained areas of intramucosal carcinoma [12]. Mixed polyps (e.g., HP/TSA/SSL or HP/adenoma) seem to have at least the same rate of progression to colorectal carcinoma as adenomas, and the risk might be higher [56, 57].

\section{Assessment of T1 adenocarcinoma}

Careful assessment in T1 adenocarcinoma is mandatory because a decision is required on local excision or a major operation. 
Size

Firstly, accurate measurement is very important, and measurement must be to the nearest millimeter (and not rounded-up to the nearest 5 or $10 \mathrm{~mm}$ ). The maximum size of the lesion should be measured from the histological slide and if the lesion is disrupted or too large, from the formalinfixed macroscopic specimen. If a biopsy is received it should be stated that size cannot be assessed.

\section{Tumour grade}

Poorly differentiated carcinomas are identified by the presence of either irregularly folded, distorted and often small tubules, or the lack of any tubular formation and showing marked cytological pleomorphism. In the absence of good evidence, we recommend that a grade of poor differentiation should be applied in a pT1 cancer when ANY area of the lesion is considered to show poor differentiation. It should be noted that this is not in accordance with the WHO classification that recommends a certain proportion of lesion showing poor differentiation before diagnosing a lesion as G3. Poor differentiation includes undifferentiated and poorly differentiated as defined by the WHO classification [58].

\section{Budding}

Budding describes the biological behaviour of the tumour at the front of invasion [59]. Budding or tumour cell dissociation [60] can be divided into slight, moderate and marked and is known from the Japanese literature of the 1950s [61] and 1990s [62].

At this time, evidence is lacking concerning reproducibility of the numerous methods for tumour budding measurement (see Table 5). It is good practice but not mandatory to document the presence or absence of single tumour cells at the front of invasion and we therefore

Table 5 Measurement of tumour budding

\begin{tabular}{|c|c|c|c|c|c|c|c|c|c|}
\hline Author & Year & $\mathrm{pT}$ & Count & Magnification & Objective & $\begin{array}{l}\text { Area } \\
\left(\mathrm{mm}^{2}\right)\end{array}$ & Classification & $\begin{array}{l}\text { Cut- } \\
\text { off }\end{array}$ & Notes \\
\hline Ueno & 2004 & & $\mathrm{H} \& \mathrm{E}$ & & $\times 20$ & 0,785 & Negative/positive & 5 & \\
\hline Ueno & 2002 & & $\mathrm{H} \& \mathrm{E}$ & & $\times 25$ & 0,385 & $<10 />10$ & 10 & Degree of grading agreement \\
\hline Ueno & 2004 & & $\mathrm{H} \& \mathrm{E}$ & 250 & $\times 25$ & 0,385 & Low $(<10) /$ high $(>10)$ & 10 & \\
\hline Shinto & 2005 & & $\begin{array}{l}\text { IHC:MNF } \\
116\end{array}$ & & $\times 20$ & & $\begin{array}{l}\text { Low }(<10) / \text { high }(>10) \\
\text { moderate }(10-19) \\
\text { severe }(>20)\end{array}$ & & $\begin{array}{l}\text { Identification of cytoplasmic } \\
\text { fragments }\end{array}$ \\
\hline Shinto & 2006 & 3 & $\begin{array}{l}\text { IHC:MNF } \\
116\end{array}$ & & $\times 20$ & & $\begin{array}{l}\text { Low }(<10) / \text { high }(>10) \\
\text { moderate }(10-19) \\
\text { severe }(>20)\end{array}$ & & $\begin{array}{l}\text { Scoring of cytoplasmic } \\
\text { fragments called now podia }\end{array}$ \\
\hline Okuyama & 2002 & 1 and 2 & $\mathrm{H} \& \mathrm{E}$ & n.a. & n.a. & n.a. & Present/absent & 1 & $\begin{array}{l}\text { Endoscopically resected } \\
\text { tumours were excluded }\end{array}$ \\
\hline Okuyama & 2003 & 3 & $\mathrm{H} \& \mathrm{E}$ & n.a. & n.a. & n.a. & Present/absent & 1 & \\
\hline Okuyama & 2003 & 3 & $\mathrm{H} \& \mathrm{E}$ & n.a. & n.a. & n.a. & Present/absent & 1 & \\
\hline Prall & 2005 & & $\begin{array}{l}\text { IHC:MNF } \\
116\end{array}$ & 250 & & 0,785 & Low/high & 25 & $\begin{array}{l}\text { ROC metastatic progression; } \\
0-120 \text { buds range; } 14 \\
\text { median } 20,46 \text { mean }\end{array}$ \\
\hline Kazama & 2006 & 1 & $\begin{array}{l}\text { IHC: CAM5.2 } \\
\text { and AE1/AE3 }\end{array}$ & n.a. & n.a. & n.a. & Present/absent & 1 & \\
\hline Kanazawa & 2007 & & $\mathrm{H} \& \mathrm{E}$ & n.a. & n.a. & n.a. & $\begin{array}{l}\text { None/mild/moderate/ } \\
\text { marked }\end{array}$ & & \\
\hline Nakamura & 2008 & & $\mathrm{H} \& \mathrm{E}$ & n.a. & n.a. & n.a. & $\begin{array}{l}\text { None } / \text { mild/low moderate/ } \\
\text { marked }=\text { high }\end{array}$ & & \\
\hline Choi & 2007 & $\begin{array}{l}2 \text { or } \\
\text { more }\end{array}$ & $\mathrm{H} \& \mathrm{E}$ & & $\times 20$ & & $(0-3) /(4-5) /(6-10) /(11-38)$ & & \\
\hline Park & 2005 & $\begin{array}{l}2 \text { or } \\
\text { more }\end{array}$ & $\mathrm{H} \& \mathrm{E}$ & & $\times 20$ & & $(0-3) /(4-5) /(6-9) /(10-38)$ & & $\begin{array}{l}\text { Mean intesity: }(+/- \text { SD) } \\
6,6+/-5,6\end{array}$ \\
\hline Hori & 2005 & & $\mathrm{H} \& \mathrm{E}$ & 200 & $\times 40$ & & & 0,05 & $\begin{array}{l}5 \% \text { of the horizontal length } \\
\text { of the invasive front }\end{array}$ \\
\hline Yasuda & 2007 & & $\mathrm{H} \& \mathrm{E}$ & & & & Present/absent & & \\
\hline Ishikawa & 2008 & & IHC:MNFIIb & 400 & & & Negative/positive & 5 & \\
\hline
\end{tabular}

Source: modified from [65, 74-79] 
recommend providing this additional information in the written report with an explanatory comment as budding has been suggested as a prognostic factor in colorectal cancer [63-65].

\section{Site}

The site of origin of each specimen should be individually identified by the clinician and reported to the pathologist on the histopathology request form. The pathologist should record this on the proforma. This is important information because the risk of lymph node metastasis from a T1 adenocarcinoma varies depending on the site and size of the lesion (rectum vs. other locations) [66].

\section{Definition of invasion}

In columnar epithelium it is difficult to define the onset of invasive carcinoma and reliably distinguish it from highgrade intraepithelial neoplasia. Criteria such as single tumour cells are more likely to be seen in more advanced carcinomas, but not in early carcinomas. Desmoplastic stromal reactions are also seldom seen in very early carcinomas. However, basal membrane structures are frequently discernible in well-differentiated early carcinomas [67-69], so that definitions using "invasion through the basement membrane" are incorrect.

The WHO definition of adenocarcinoma in use when the EU guidelines were developed excluded diagnosis of intramucosal carcinoma in the colon or rectum, in contrast to the accepted WHO definitions for the stomach, oesophagus and small bowel. In the latter cases, a decision on surgical versus local therapy is made based on respective protocols. Comparable lesions in the colon and rectum are reported as high-grade mucosal neoplasia, because a carcinoma in the colon is defined by infiltration of the submucosa, according to the WHO classification.

The discussion on this issue among the authors of the pathology chapter in the EU Guidelines reflects, among other things, concern about potential overtreatment of early $\mathrm{T} 1$ carcinomas which are detected much more frequently in a screening setting. The clinical management of a lesion where invasion of the lamina propria has occurred is no different from that where high-grade changes are confined to the glands. This legitimate concern as to increased morbidity and mortality due to miscommunication of diagnostic criteria may be dealt with more effectively in the future, as multidisciplinary management of lesions detected in and outside of screening programmes advances. The authors hope that such advances and their effective dissemination will be stimulated by the publication of the new EU guidelines. This, in turn, may lead to revision of the current WHO definition of colorectal adenocarcinoma in a future revision of the WHO classification of gastrointestinal tumours. Pathologists should report on what version of the WHO and TNM classifications their diagnosis is based.

In those cases in which intramucosal colorectal cancer is suspected, and particularly in countries in which this diagnosis is documented in addition to the WHO terminology, explicit comments by the pathologist are recommended. Based on the cytological characteristics of the case, the pathologist should indicate whether local endoscopic or surgical removal is recommended, and the basis for this recommendation should be indicated. This recommendation should be discussed in a multidisciplinary conference prior to surgery. The Japanese criteria for such stratification have been published [55]. The updated Paris classification based on a workshop in Feb 2008 in Kyoto [9] permits such subclassification based on improved grouping and explains in detail the grading criteria [10].

The use of the term carcinoma in situ introduced by the TNM system is inadequate because the criteria are too vague and cannot be used for columnar epithelium.

A subclassification of all carcinomas into low-risk and high-risk based on risk of lymph node involvement should always be undertaken. For exact criteria please see main text of the present publication and Chapter 7 of the full GL document [1] and the updated Paris classification $[9,10]$.

\section{Perineural invasion}

Perineural invasion (PNI) was recently described as an independent risk factor for colorectal cancer [66, 70]. PNI is significantly associated with high tumour stage, grade and metastases. Furthermore, PNI serves as an independent predictor of disease-free and cancer survival [66, 70]. Recently, an association with other criteria indicating an aggressive course of disease such as lymphatic vessel permeation, venous invasion, tumour growth pattern, budding [71] were described by Poeschl et al. [66]. Also, it was described that PNI-positive tumours are more likely to be incompletely resected, and more likely to progress after Mayo regimen chemotherapy than PNI-negative tumours. Lately, Poeschl et al. were able to show that PNI is an additional independent factor for local tumour relapse.

It is recommended to record PNI in routine sections of colorectal cancer. According to recent studies [66, 70, 72, 73], immunohistochemistry or special stains are not necessary to detect PNI. Prospective studies are needed to show the clinical relevance of PNI, its relationship to other features such as lymphatic and vascular invasion and the benefit of alternative treatment for such more aggressive tumours that are PNI positive. 


\section{Conclusions}

The rapid pace of developments in screening, diagnosis and treatment of colorectal cancer is likely to continue unabated in the coming years. Pathologists interested in colorectal cancer should be aware of the topics likely to be of future relevance to quality assurance. This may help to recognise opportunities to continuously improve the quality and performance of current screening and diagnostic activities.

Acknowledgements We thank the following external reviewers for reading and providing helpful comments and suggestions on the draft chapter and annex on quality assurance in pathology in colorectal cancer screening and diagnosis during the preparation of the full guidelines document: Robert Riddell, Toronto, Canada; Hiroshi Saito, Tokyo and Hidenobu Watanabe, Niigata, Japan.

The comments and suggestions received from consultation of the European Cancer Network are gratefully acknowledged.

Phil Quirke is supported by Yorkshire Cancer Research and the Department of Health/Cancer Research UK Experimental Cancer Medicine Centre Initiative

Financial support of the European Communities through the EU Public Health Programme (Development of European Guidelines for Quality Assurance of Colorectal Cancer Screening (CRC), grant agreement No. 2005317), of the Public Affairs Committee of the United European Gastroenterology Federation, and from a cooperative agreement between the American Cancer Society and the Division of Cancer Prevention and Control at the Centers for Disease Control and Prevention is gratefully acknowledged.

The technical support of Tracy Lignini, Krittika Guinot and Simon Ducarroz at the International Agency for Research on Cancer in the preparation of the manuscript is gratefully acknowledged.

Conflict of interest Pathology and tumour biology at the Leeds Institute of Molecular Medicine, led by Philip Quirke, at the University of Leeds has received funding from the EU Public Health Programme (Development of European Guidelines for Quality Assurance of Colorectal Cancer Screening (CRC), grant agreement No. 2005317) to develop a prototype web-based training tool for pathology in colorectal cancer screening.

The International Agency for Research on Cancer, where Lawrence von Karsa is employed, is a recipient of research grants from the EU Public Health Programme.

Open Access This article is distributed under the terms of the Creative Commons Attribution Noncommercial License which permits any noncommercial use, distribution, and reproduction in any medium, provided the original author(s) and source are credited.

\section{References}

1. Quirke P, Risio M, Lambert R, Vieth M (2010) Quality assurance in pathology in colorectal cancer screening and diagnosis. In: Segnan N, Patnick J, von Karsa L (eds) European Guidelines for Quality Assurance in Colorectal Cancer Screening and Diagnosis - First Edition (In press)

2. Vieth M, Quirke P, Lambert R, von Karsa L, Risio M (2010) Annotations of colorectal lesions. In: Segnan N, Patnick J, von
Karsa L (eds) European Guidelines for Quality Assurance in Colorectal Cancer Screening and Diagnosis - First Edition, (In press)

3. Schlemper RJ, Riddell RH, Kato Y, Borchard F, Cooper HS, Dawsey SM, Dixon MF, Fenoglio-Preiser CM, Flejou JF, Geboes K, Hattori T, Hirota T, Itabashi M, Iwafuchi M, Iwashita A, Kim YI, Kirchner T, Klimpfinger M, Koike M, Lauwers GY, Lewin KJ, Oberhuber G, Offner F, Price AB, Rubio CA, Shimizu M, Shimoda T, Sipponen P, Solcia E, Stolte M, Watanabe H, Yamabe H (2000) The Vienna classification of gastrointestinal epithelial neoplasia. Gut 47(2):251-255

4. Schlemper RJ, Kato Y, Stolte M (2001) Review of histological classifications of gastrointestinal epithelial neoplasia: differences in diagnosis of early carcinomas between Japanese and Western pathologists. J Gastroenterol 36(7):445-456

5. Schlemper RJ, Kato Y, Stolte M (2000) Diagnostic criteria for gastrointestinal carcinomas in Japan and Western countries: proposal for a new classification system of gastrointestinal epithelial neoplasia. J Gastroenterol Hepatol 15(Suppl):G49G57

6. Wolber RA, Owen DA (1991) Flat adenomas of the colon. Hum Pathol 22(1):70-74

7. Ajioka Y, Watanabe H, Kobayashi M, Maeo S, Yoshida M (1994) Macroscopic classification of colorectal (minute) neoplasia. I to Cho 29:89

8. Ajioka Y, Watanabe H, Kazama S, Hashidate H, Yokoyama J, Yamada S, Takaku H, Nishikura K (2000) Early colorectal cancer with special reference to the superficial nonpolypoid type from a histopathologic point of view. World J Surg 24(9):1075-1080

9. Kudo S, Lambert R, Allen JI, Fujii H, Fujii T, Kashida H, Matsuda T, Mori M, Saito H, Shimoda T, Tanaka S, Watanabe H, Sung JJ, Feld $\mathrm{AD}$, Inadomi JM, O’Brien MJ, Lieberman DA, Ransohoff DF, Soetikno RM, Triadafilopoulos G, Zauber A, Teixeira CR, Rey JF, Jaramillo E, Rubio CA, Van GA, Jung M, Vieth M, Jass JR, Hurlstone PD (2008) Nonpolypoid neoplastic lesions of the colorectal mucosa. Gastrointest Endosc 68(4 Suppl):S3-S47

10. Lambert R, O’Brien MJ, Jaramillo E, Vieth M (2009) The serrated pathway to colorectal cancer. World Gastroenterology News 14 (2):5-10

11. Oono Y, Fu K, Nakamura H, Iriguchi Y, Yamamura A, Tomino Y, Oda J, Mizutani M, Takayanagi S, Kishi D, Shinohara T, Yamada K, Matumoto J, Imamura K (2009) Progression of a sessile serrated adenoma to an early invasive cancer within 8 months. Dig Dis Sci 54(4):906-909

12. Longacre TA, Fenoglio-Preiser CM (1990) Mixed hyperplastic adenomatous polyps/serrated adenomas. A distinct form of colorectal neoplasia. Am J Surg Pathol 14(6):524-537

13. Atkin W, Valori R, Kuipers EJ, Hoff G, Senore C, Segnan N, Jover R, Schmiegel W, Lambert R, Pox C (2010) Colonoscopic surveillance after adenoma removal. In: Segnan N, Patnick J, von Karsa L (eds) European Guidelines for Quality Assurance in Colorectal Cancer Screening and Diagnosis - First Edition, (In press)

14. Steele RJC, Pox C, Kuipers EJ, Minoli G, Lambert R (2010) Management of screen-detected lesions. In: Segnan N, Patnick J, von Karsa L (eds) European Guidelines for Quality Assurance in Colorectal Cancer Screening and Diagnosis - First Edition, (In press)

15. O'Brien MJ (2007) Hyperplastic and serrated polyps of the colorectum. Gastroenterol Clin North Am 36(4):947-968, viii

16. O'Brien MJ, Yang S, Huang CS, Shepherd C, Cerda S, Farraye F (2008) The serrated polyp pathway to colorectal carcinoma. Diagn Histopathol 14(2):78-93

17. Torlakovic E, Skovlund E, Snover DC, Torlakovic G, Nesland JM (2003) Morphologic reappraisal of serrated colorectal polyps. Am J Surg Pathol 27(1):65-81 
18. Higuchi T, Jass JR (2004) My approach to serrated polyps of the colorectum. J Clin Pathol 57(7):682-686

19. Torlakovic E, Snover DC (1996) Serrated adenomatous polyposis in humans. Gastroenterology 110(3):748-755

20. Oka S, Tanaka S, Hiyama T, Ito M, Kitadai Y, Yoshihara M, Haruma K, Chayama K (2004) Clinicopathologic and endoscopic features of colorectal serrated adenoma: differences between polypoid and superficial types. Gastrointest Endosc 59(2):213-219

21. Jaramillo E, Tamura S, Mitomi H (2005) Endoscopic appearance of serrated adenomas in the colon. Endoscopy 37(3):254-260

22. Wong NA, Hunt LP, Novelli MR, Shepherd NA, Warren BF (2009) Observer agreement in the diagnosis of serrated polyps of the large bowel. Histopathology 55(1):63-66

23. Jass JR (2007) Classification of colorectal cancer based on correlation of clinical, morphological and molecular features. Histopathology 50(1):113-130

24. Grady WM, Carethers JM (2008) Genomic and epigenetic instability in colorectal cancer pathogenesis. Gastroenterology 135(4):1079-1099

25. Samowitz WS, Slattery ML, Sweeney C, Herrick J, Wolff RK, Albertsen H (2007) APC mutations and other genetic and epigenetic changes in colon cancer. Mol Cancer Res 5(2):165-170

26. Kawasaki T, Ohnishi M, Nosho K, Suemoto Y, Kirkner GJ, Meyerhardt JA, Fuchs CS, Ogino S (2008) CpG island methylator phenotype-low (CIMP-low) colorectal cancer shows not only few methylated CIMP-high-specific $\mathrm{CpG}$ islands, but also low-level methylation at individual loci. Mod Pathol 21(3):245-255

27. Ogino S, Goel A (2008) Molecular classification and correlates in colorectal cancer. J Mol Diagn 10(1):13-27

28. Ogino S, Kawasaki T, Kirkner GJ, Loda M, Fuchs CS (2006) CpG island methylator phenotype-low (CIMP-low) in colorectal cancer: possible associations with male sex and KRAS mutations. J Mol Diagn 8(5):582-588

29. Ogino S, Kawasaki T, Kirkner GJ, Kraft P, Loda M, Fuchs CS (2007) Evaluation of markers for CpG island methylator phenotype (CIMP) in colorectal cancer by a large population-based sample. J Mol Diagn 9(3):305-314

30. Shen L, Toyota M, Kondo Y, Lin E, Zhang L, Guo Y, Hernandez NS, Chen X, Ahmed S, Konishi K, Hamilton SR, Issa JP (2007) Integrated genetic and epigenetic analysis identifies three different subclasses of colon cancer. Proc Natl Acad Sci USA 104 (47):18654-18659

31. Suehiro Y, Wong CW, Chirieac LR, Kondo Y, Shen L, Webb CR, Chan YW, Chan AS, Chan TL, Wu TT, Rashid A, Hamanaka Y, Hinoda Y, Shannon RL, Wang X, Morris J, Issa JP, Yuen ST, Leung SY, Hamilton SR (2008) Epigenetic-genetic interactions in the APC/WNT, RAS/RAF, and P53 pathways in colorectal carcinoma. Clin Cancer Res 14(9):2560-2569

32. Toyota M, Ohe-Toyota M, Ahuja N, Issa JP (2000) Distinct genetic profiles in colorectal tumors with or without the $\mathrm{CpG}$ island methylator phenotype. Proc Natl Acad Sci USA 97(2):710-715

33. Toyota M, Ahuja N, Ohe-Toyota M, Herman JG, Baylin SB, Issa JP (1999) CpG island methylator phenotype in colorectal cancer. Proc Natl Acad Sci USA 96(15):8681-8686

34. Ogino S, Nosho K, Kirkner GJ, Kawasaki T, Meyerhardt JA, Loda M, Giovannucci EL, Fuchs CS (2009) CpG island methylator phenotype, microsatellite instability, BRAF mutation and clinical outcome in colon cancer. Gut 58(1):90-96

35. Carr NJ, Mahajan H, Tan KL, Hawkins NJ, Ward RL (2009) Serrated and non-serrated polyps of the colorectum: their prevalence in an unselected case series and correlation of BRAF mutation analysis with the diagnosis of sessile serrated adenoma. J Clin Pathol 62(6):516-518

36. Jass JR, Baker K, Zlobec I, Higuchi T, Barker M, Buchanan D, Young J (2006) Advanced colorectal polyps with the molecular and morphological features of serrated polyps and adenomas: concept of a 'fusion' pathway to colorectal cancer. Histopathology 49(2):121-131

37. Goldstein NS, Bhanot P, Odish E, Hunter S (2003) Hyperplasticlike colon polyps that preceded microsatellite-unstable adenocarcinomas. Am J Clin Pathol 119(6):778-796

38. Higuchi T, Sugihara K, Jass JR (2005) Demographic and pathological characteristics of serrated polyps of colorectum. Histopathology 47(1):32-40

39. Montgomery E (2004) Serrated colorectal polyps: emerging evidence suggests the need for a reappraisal. Adv Anat Pathol 11(3):143-149

40. Farris AB, Misdraji J, Srivastava A, Muzikansky A, Deshpande V, Lauwers GY, Mino-Kenudson M (2008) Sessile serrated adenoma: challenging discrimination from other serrated colonic polyps. Am J Surg Pathol 32(1):30-35

41. Sandmeier D, Seelentag W, Bouzourene H (2007) Serrated polyps of the colorectum: is sessile serrated adenoma distinguishable from hyperplastic polyp in a daily practice? Virchows Arch 450 (6):613-618

42. Owens SR, Chiosea SI, Kuan SF (2008) Selective expression of gastric mucin MUC6 in colonic sessile serrated adenoma but not in hyperplastic polyp aids in morphological diagnosis of serrated polyps. Mod Pathol 21(6):660-669

43. Torlakovic EE, Gomez JD, Driman DK, Parfitt JR, Wang C, Benerjee T, Snover DC (2008) Sessile serrated adenoma (SSA) vs. traditional serrated adenoma (TSA). Am J Surg Pathol 32(1):21-29

44. Sheridan TB, Fenton H, Lewin MR, Burkart AL, IacobuzioDonahue CA, Frankel WL, Montgomery E (2006) Sessile serrated adenomas with low- and high-grade dysplasia and early carcinomas: an immunohistochemical study of serrated lesions "caught in the act". Am J Clin Pathol 126(4):564-571

45. Noffsinger AE (2009) Serrated polyps and colorectal cancer: new pathway to malignancy. Annu Rev Pathol 4:343-364

46. Schreiner MA, Weiss DG, Lieberman DA (2010) Proximal and large hyperplastic and nondysplastic serrated polyps detected by colonoscopy are associated with neoplasia. Gastroenterology 139 (5):1497-1502

47. Schmiegel W, Reinacher-Schick A, Arnold D, Graeven U, Heinemann V, Porschen R, Riemann J, Rodel C, Sauer R, Wieser M, Schmitt W, Schmoll HJ, Seufferlein T, Kopp I, Pox C (2008) Update S3-guideline "colorectal cancer". Z Gastroenterol 46 (8):799-840

48. Williams GT, Quirke P, Shepherd NA (2007) Dataset for colorectal cancer, 2nd edn - Appendix D: Proforma for local excision specimens. http://www.rcpath.org/resources/worddocs/ G049ColorectalDatasetAppendixD-Sep07.doc

49. Williams GT, Quirke P, Shepherd NA (2007) Dataset for colorectal cancer, 2nd edn - Appendix C: Proforma for colorectal cancer resections. http://www.rcpath.org/resources/worddocs/ G049ColorectalDatasetAppendixC-Sep07.doc

50. Williams GT, Quirke P, Shepherd NA (2007) Dataset for colorectal cancer, 2nd edn. http://www.rcpath.org/resources/pdf/ G049-ColorectalDataset-Sep07.pdf

51. NHS Bowel Cancer Screening Programme (2007) Reporting lesions in the NHS Bowel Cancer Screening Programme guidelines from the Bowel Cancer Screening Programme Pathology Group. http://www.cancerscreening.nhs.uk/bowel/ publications/nhsbcsp01.pdf

52. WHO (2000) Pathology and genetics of tumours in the digestive system. Carcinoma of the colon and rectum. In: Hamilton SR, Aaltonen LA (eds) World Health Organization International Histological Classification of Tumours. IARC, Lyon, pp 105-119

53. Snover DC, Jass JR, Fenoglio-Preiser C, Batts KP (2005) Serrated polyps of the large intestine: a morphologic and molecular review of an evolving concept. Am J Clin Pathol 124(3):380-391 
54. Spring KJ, Zhao ZZ, Karamatic R, Walsh MD, Whitehall VL, Pike T, Simms LA, Young J, James M, Montgomery GW, Appleyard M, Hewett D, Togashi K, Jass JR, Leggett BA (2006) High prevalence of sessile serrated adenomas with BRAF mutations: a prospective study of patients undergoing colonoscopy. Gastroenterology 131(5):1400-1407

55. Watanabe H, Suda T (1984) Precancerous lesions of the colon and rectum. Gan To Kagaku Ryoho 11(1):1-9

56. Hyman NH, Anderson P, Blasyk H (2004) Hyperplastic polyposis and the risk of colorectal cancer. Dis Colon Rectum 47(12):2101-2104

57. Leggett BA, Devereaux B, Biden K, Searle J, Young J, Jass J (2001) Hyperplastic polyposis: association with colorectal cancer. Am J Surg Pathol 25(2):177-184

58. Washington MK, Berlin J, Branton P, Burgart LJ, Carter DK, Fitzgibbons PL, Halling K, Frankel W, Jessup J, Kakar S, Minsky B, Nakhleh R, Compton CC (2009) Protocol for the examination of specimens from patients with primary carcinoma of the colon and rectum. Arch Pathol Lab Med 133(10):1539-1551

59. Deinlein P, Reulbach U, Stolte M, Vieth M (2003) Risk factors for lymphatic metastasis from pT1 colorectal adenocarcinoma. Pathologe 24(5):387-393

60. Gabbert HE, Meier S, Gerharz CD, Hommel G (1992) Tumor-cell dissociation at the invasion front: a new prognostic parameter in gastric cancer patients. Int J Cancer 50(2):202-207

61. Imai $T$ (1954) The growth of human carcinoma: a morphological analysis. Fukuoka Igaku Zasshi 45:13-43

62. Kobayashi M, Watanabe H, Maeo S, Ajioka Y, Yoshida M (1994) Correlation of histological atypia and cancer-sprouting with vascular permeation and lymph nodal metastasis by our new histological classification of submucosal invasion by colorectal carcinomas. Stomach Intest 29:1151-1156

63. Ogawa T, Yoshida T, Tsuruta T, Tokuyama W, Adachi S, Kikuchi M, Mikami T, Saigenji K, Okayasu I (2009) Tumor budding is predictive of lymphatic involvement and lymph node metastases in submucosal invasive colorectal adenocarcinomas and in nonpolypoid compared with polypoid growths. Scand J Gastroenterol 44(5):605-614

64. Sy J, Fung CL, Dent OF, Chapuis PH, Bokey L, Chan C (2010) Tumor budding and survival after potentially curative resection of node-positive colon cancer. Dis Colon Rectum 53(3):301-307

65. Nakamura T, Mitomi H, Kanazawa H, Ohkura Y, Watanabe M (2008) Tumor budding as an index to identify high-risk patients with stage II colon cancer. Dis Colon Rectum 51(5):568-572

66. Poeschl EM, Pollheimer MJ, Kornprat P, Lindtner RA, Schlemmer A, Rehak P, Vieth M, Langner C (2010) Perineural invasion: correlation with aggressive phenotype and independent prognostic variable in both colon and rectum cancer. J Clin Oncol 28(21):e358-e360

67. Borchard F (2000) Forms and nomenclature of gastrointestinal epithelial expansion: what is invasion? Verh Dtsch Ges Pathol 84:50-61

68. Borchard F, Heilmann KL, Hermanek P, Gebbers JO, Heitz PU, Stolte M, Pfeifer U, Schaefer HE, Wiebecke B, Schlake W (1991) Definition and clinical significance of dysplasia in the digestive tract\$ Results of a meeting of the Society of Gastroenterologic Pathology of the German Society of Pathology 25 November 1989 in Kronberg. Pathologe 12(1):50-56

69. Vieth M, Stolte M (2005) Distinction of high-grade intraepithelial neoplasia and tubular gastric adenocarcinoma. In: Kaminishi M, Takubo K, Mafune K (eds) The diversity of gastric carcinoma: pathogenesis, diagnosis and therapy. Springer, Tokyo, pp 109-116

70. Liebig C, Ayala G, Wilks J, Verstovsek G, Liu H, Agarwal N, Berger DH, Albo D (2009) Perineural invasion is an independent predictor of outcome in colorectal cancer. J Clin Oncol 27(31):5131-5137

71. Jass JR, Love SB, Northover JM (1987) A new prognostic classification of rectal cancer. Lancet 1(8545):1303-1306

72. Liebig C, Ayala G, Wilks JA, Berger DH, Albo D (2009) Perineural invasion in cancer: a review of the literature. Cancer 115(15):3379-3391

73. Marshall CL, Liebig C, Wilks J, Agarwal N, Berger DH, Albo D, Ayala G, Verstovsek G, Liu H (2010) Reply to E.M. Poeschl et al. J Clin Oncol 28(21):e361-e363

74. Cooper HS, Deppisch LM, Gourley WK, Kahn EI, Lev R, Manley PN, Pascal RR, Qizilbash AH, Rickert RR, Silverman JF (1995) Endoscopically removed malignant colorectal polyps: clinicopathologic correlations. Gastroenterology 108(6):1657-1665

75. Haggitt RC, Glotzbach RE, Soffer EE, Wruble LD (1985) Prognostic factors in colorectal carcinomas arising in adenomas: implications for lesions removed by endoscopic polypectomy. Gastroenterology 89(2):328-336

76. Konishi F, Morson BC (1982) Pathology of colorectal adenomas: a colonoscopic survey. J Clin Pathol 35(8):830-841

77. Nascimbeni R, Burgart LJ, Nivatvongs S, Larson DR (2002) Risk of lymph node metastasis in T1 carcinoma of the colon and rectum. Dis Colon Rectum 45(2):200-206

78. Ueno H, Mochizuki H, Hashiguchi Y, Shimazaki H, Aida S, Hase K, Matsukuma S, Kanai T, Kurihara H, Ozawa K, Yoshimura K, Bekku S (2004) Risk factors for an adverse outcome in early invasive colorectal carcinoma. Gastroenterology 127(2):385-394

79. Volk EE, Goldblum JR, Petras RE, Carey WD, Fazio VW (1995) Management and outcome of patients with invasive carcinoma arising in colorectal polyps. Gastroenterology 109(6):1801-1807 